\title{
Research on the Drought Tolerance Mechanism of Pennisetum Glaucum (L.) in the Root During Seedling
}

\section{Ailing Zhang}

Department of Grassland Science, Faculty of Animal Science and Technology, Sichuan Agricultural University

\section{Yang Ji}

Sichuan Animal Science Academy

\section{Min Sun}

Department of Grassland Science, Faculty of Animal Science and Technology, Sichuan Agricultural University

\section{Chuang Lin}

Department of Grassland Science, Faculty of Animal Science and Technology, Sichuan Agricultural University

\section{Puding Zhou}

Department of Grassland Science, Faculty of Animal Science and Technology, Sichuan Agricultural University

\section{Juncai Ren}

College of Animal Science and Technology, Rongchang Campus, Southwest University

\section{Dan Luo}

Department of Grassland Science, Faculty of Animal Science and Technology, Sichuan Agricultural University

\section{Xiaoshan Wang}

Department of Grassland Science, Faculty of Animal Science and Technology, Sichuan Agricultural University

\section{Encong Ma}

Department of Grassland Science, Faculty of Animal Science and Technology, Sichuan Agricultural University

\section{Linkai Huang ( $\square$ huanglinkai@sicau.edu.cn )}

Department of Grassland Science, Faculty of Animal Science and Technology, Sichuan Agricultural University

\section{Research Article}


Keywords: pearl millet, root, transcriptome, MAPK signaling pathway, plant hormone signal transduction, ABA

Posted Date: December 29th, 2020

DOI: https://doi.org/10.21203/rs.3.rs-129151/v1

License: (c) (1) This work is licensed under a Creative Commons Attribution 4.0 International License. Read Full License

Version of Record: A version of this preprint was published at BMC Genomics on July 23rd, 2021. See the published version at https://doi.org/10.1186/s12864-021-07888-5. 


\title{
Research on the drought tolerance mechanism of Pennisetum glaucum (L.) in the root during seedling
}

\author{
Ailing Zhang ${ }^{1 *}$, Yang Ji²*, Min Sun ${ }^{1 *}$, Chuang Lin ${ }^{1 *}$, Puding Zhou${ }^{1}$, Juncai Ren ${ }^{3}$, Dan Luo ${ }^{1}$, \\ Xiaoshan Wang ${ }^{1}$, Encong Ma ${ }^{1}$, Linkai Huang ${ }^{1 * *}$ \\ ${ }^{1}$ Department of Grassland Science, Faculty of Animal Science and Technology, Sichuan \\ Agricultural University, Chengdu 611130, China \\ ${ }^{2}$ Sichuan Animal Science Academy, Chengdu 610066, China \\ ${ }^{3}$ College of Animal Science and Technology, Rongchang Campus, Southwest University, \\ Chongqing, 402460, China \\ *Ailing Zhang, Yang Ji, Min Sun and Chuang Lin contributed equally to this work \\ **Corresponding Author: huanglinkai@sicau.edu.cn
}

\begin{abstract}
Background: Drought, being as one of the major environmental limiting factors, leads a huge reduction in crop growth rate and biomass accumulation. Pearl millet is a suitable material to study drought resistance due to its excellent drought tolerance. Root is a very important part of plant playing crucial roles in plant growth and development, which makes it a target to research on.

Results: In this study, we tried to find the mechanism of drought tolerance of pearl millet by comparing the data of physiology and transcriptome under normal and drought conditions at 3 time points (1 hour, 3 hours and 7 hours) in root at seedling stage. The relative electrical conductivity went up from 1hour to 7 hours in both control and drought stress groups and the content of malondialdehyde showed a decreasing trend. 2004, 1538 and 605 differently expressed genes were found at 1hour, 3 hours and 7 hours respectively. Some of these differently expressed genes were clustered significantly into 'metabolic processes', 'MAPK signaling pathway' and 'plant hormone signal transduction' like ABA signal transduction pathway in GO and KEGG enrichment analysis.

Conclusions: Pearl millet was found to have a rapid drought response, which may occur before 1 hour contributing to its drought tolerance. These results can provide a theoretical basis to enhance drought resistance in other plants.
\end{abstract}

Keywords: pearl millet, root, transcriptome, MAPK signaling pathway, plant hormone signal transduction, ABA

\section{Introduction}

Drought is one of the major environment constraints limiting agricultural production worldwide, which lead to the lack of enough moisture that required for plant growth and development to realize their life cycle (Chen et al., 2020; Dennis and Bruening, 2000; Ji et al., 2018a; Ji et al., 2018b; 
Lambers et al., 2008; Manivannan et al., 2008; Rollins et al., 2013). Drought stress severely affects growth and development of plants by causing substantial reductions in crop growth rate and biomass accumulation. The main consequences of drought stress in plants are reduced rate of cell division and expansion, root proliferation, stem elongation and leaf size. Nevertheless, it also disturbed stomatal oscillations, plant water and nutrient relations with diminished crop productivity, and water use efficiency (Anjum et al., 2011a; Farooq et al., 2009; Li et al., 2009b). It has been reported that drought has had a bad influence on many crops. For example, rice (Oryza sativa L.) suffered a drastic yield reduction range $18 \%-60 \%$ even more than $70 \%$ in some places due to water deficiency (Bernier et al., 2007; Dixit et al., 2014; Dixit et al., 2012; Ghimire et al., 2012; Sandhu et al., 2014; Vikram et al., 2011) while it caused 10\%-50\% reduction on wheat (Triticum aestivum L.) (Amir et al., 2011; Praba et al., 2009; Wang et al., 2003). Meanwhile, the biomass of maize (Zea mays L.) decreased 1\%-76\% when facing drought stress (Adebayo and Menkir, 2015; Adee et al., 2016; Daryanto et al., 2016) and barley (Hordeum vulgare L.) reduced 73\%-87\% (Samarah et al., 2009). And crops like chickpea (Cicer arietinum Linn.), pigeon pea (Cajanus cajan (Linn.) Millsp.) and canola (Brassica napus L.) planted on the dry lands were also shown to have a huge yield reduction (Sandhu and Kumar, 2017). These reports indicate that drought stress can lead to huge loss of economy which will depress the living quality of humans (Sandhu and Kumar, 2017). What's worse, many researchers predicted that the dry land would expand globally by the end of this century and was $5.8 \times 10^{6} \mathrm{~km}^{2}$ (or about 10\%) larger than that in 1961-1990 because of increasing concentrations of greenhouse gases in the atmosphere. And the major expansion of arid regions will occur over southwest North America, southern Africa, the northern fringe of Africa, and Australia, while major expansions of semiarid regions will occur across southern Africa, North and South America and the north side of the Mediterranean (Dai and Aiguo, 2013; Feng and Fu, 2013; Prudhomme et al., 2014). Therefore, it's urgent to promote the drought stress tolerance of corps.

Pearl millet (Pennisetum glaucum (L.) R. Br.), as the sixth most crucial cereal crops after rice, wheat, maize, barley and sorghum (Sorghum bicolor (L.) Moench) in the world (Awan et al., 2020; Dan et al., 2020; Khan et al., 2020a; Khan et al., 2019a; Khan et al., 2020b; Khan et al., 2019b; Shivhare and Lata, 2016; Sun et al., 2020), is cultivated on 27 million hectares worldwide as a staple food crop in arid and semi-arid regions of sub-Saharan Africa, India and South Asia where grain yields average $900 \mathrm{~kg} / \mathrm{ha} \mathrm{(Andrews} \mathrm{and} \mathrm{Kumar,} \mathrm{1992;} \mathrm{Varshney} \mathrm{et} \mathrm{al.,} \mathrm{2017).} \mathrm{It} \mathrm{feeds} \mathrm{more} \mathrm{than} 90$ million farmers living in poverty with high nutritious (8-19\% protein), high fiber $(1.2 \mathrm{~g} / 100 \mathrm{~g})$, low starch, and higher micronutrient concentrations (iron and zinc) than wheat, rice, sorghum and maize (Varshney et al., 2017). Planted on the dryland often makes pearl millet possess excellent drought resistance, at the same time, it is also tolerant to heat, salinity and soil nutrient deficiency (Andrews and Kumar, 1992; Reddy et al., 2017; Vadez et al., 2012). To study about the drought resistant mechanism in pearl millet and to dig out key role genes related to drought tolerance are very important for pearl millet to acclimate to severer water deficit environment in the future, which can decrease the economic loss especially for poor area where pearl millet is used as main staple food. Besides, it is also beneficial for genetic improvement to raise drought tolerance of other crops.

Root is one of the most important tissues of plants to realize a water uptake and transport and it is sensitive to water deficiency (Bertin et al., 2003). And a main challenge in developing droughtresistant plants is elucidating how roots can better meet increased evapotranspiration demands of the canopy with lower soil water availability, which means studying about drought tolerance in root 
is an important side. At the other side, plant establishment at seedling stage decides its quality for later growth (Huang and Fry, 1998). Transcriptomic analysis under next generation sequencing (NGS) is an efficient approach for exploring gene expression profiling. And RNA Sequencing (RNA-Seq) based on NGS has been utilized as a comprehensive high-throughput approach to reveal the gene expression variation, regulatory networks, and some technology development in various species (Ambika et al., 2018; Lin et al., 2019; Shuping et al., 2020; Sifan et al., 2018; Yan et al., 2019; Zhou et al., 2019). In this study, RNA-Seq was performed to detect the seedling stage expression pattern of root at early phases with three time points $(1,3$ and 7 hours after drought treatment) under drought stress. At present, three studies have investigated drought resistance in pearl millet using transcriptomic methods (Ambika et al., 2018; Choudhary et al., 2015; Mishra et al., 2007). However, none of them carried out a varied gene expression under drought stress as time went on, which is significant because at different times, there may be different major genes.

In this study, we analyzed genes that expressed differently after drought treatment at 3 different time points ( $1 \mathrm{~h}, 3 \mathrm{~h}$ and $7 \mathrm{~h}$ ) in the root of pearl millet at seedling. From analysis of these transcriptome data, we aimed to reveal the early dynamic molecular regulation of pearl millet when attacked by the water deficit and to find out the key genes which conducted the drought tolerance. This is also important for drought enhancement of other crops. And at present, there is no report about the early dynamic mechanism of drought response in the root of pearl millet

\section{Materials and methods}

\section{Plant growth and water treatment}

A cultivar of pearl millet 'Tifleaf 3' (obtained from Sichuan Agricultural University) was used for later experiments. Twenty plastic pots $(10 * 15 \mathrm{~cm})$ were filled with half silica sand where $0.2 \mathrm{~g}$ seeds (about 240 seeds) were bespread on the silica sand for each pot. The materials were cultivated in the growth chamber which was set a day ( 14 hours)/night ( 10 hours) temperature regime of $26 / 22^{\circ} \mathrm{C}$. In the first three days, these materials were watered with distilled water about the lower half of the seed and most of them (about 85\%) sprouted on the third day. From the fourth day, they were watered with Hoagland solution $(0.5 \times)$. After 13 days growth (most of plants with three leaves), the Hoagland solution of 10 pots was changed as $20 \%$ PEG (dissolve 200g PEG (polyethylene glycol 6000 ) in $0.5 \times$ Hoagland solution to make $1000 \mathrm{~mL}$ ) which could simulate drought stress. Root samples with similar growth vigour of plants were collected randomly after 1, 3 and 7 hours of drought treatment containing treatment groups and control groups with 3 replicates each and were frozen immediately in liquid nitrogen and stored at $-80{ }^{\circ} \mathrm{C}$ for further experiment.

\section{RNA-seq and data analysis}

A NanoDrop spectrophotometer (California, USA) used to detect the purity of RNA, and a Qubit RNA assay kit in a Qubit 2.0 fluorometer system (California, USA) was used to determine the concentration of RNA. The library was constructed by the NEBNext ${ }^{\circledR}$ UltraTM Directional RNA Library Prep Kit for Illumina ${ }^{\circledR}$ (California, USA). The mRNA was enriched by The NEBNext ${ }^{\circledR}$ Poly (A) mRNA Magnetic Isolation Module while the break of mRNA into short segments was using Fragmentation Buffer. A strand of cDNA was synthesized with random hexamer primers and the second strand of it was synthesized by adding buffer, DNA polymerase I and dNTPs. Both strand 
cDNA was purified by AMPure XP beads, which was repaired at the end. A tail was added and sequenced. Then, fragment size was selected by AMPure XP beads. At last, the final cDNA library was gained by PCR enrichment. Qubit 2.0 was used for preliminary quantification and Agilent 2100 was used to test the inserted fragments of the library. Furthermore, Illumina Hi-Seq 2000 was used for sequencing. We established a total of 18 RNA-Seq libraries.

Identification of gene expression level of each sample used RSEM (Li et al., 2009a). The clean data produced by Illumina sequencing were mapped to SMRT sequencing data of pearl millet (Sun et al., 2020), and the read count of each gene was gained from the mapping results ( $\mathrm{Li}$ and Dewey, 2011). The read count value of each gene was converted to the FPKM value (Fragments per Kilobase Million).

Differential expression analysis of two groups was performed using the DESeq2 R package (1.16.1) and genes with an adjusted P-value $<0.05$ and $\left|\log _{2}(\mathrm{FC})\right| \geq 1$ found by DESeq2 were assigned as differentially expressed. Gene Ontology (GO) enrichment analysis of differentially expressed genes (DEGs) obtained was implemented by the cluster Profiler R package. Besides, GO terms with corrected P-value less than 0.05 were thought enriched significantly. Finally, the cluster Profiler R package was used to test the statistical enrichment of DEGs in KEGG pathways.

A weighted gene co-expression network analysis (WGCNA) was carried out by the WGCNA package in R (v3.3.0) (Langfelder and Horvath, 2008).

\section{Results}

After treatments, root samples were collected to measure the relative electrical conductivity and the content of malondialdehyde (MDA). The results (Figure 1) showed that as time prolonged, relative electrical conductivity went up in both $\mathrm{CK}$ and drought stress groups. And after a short time of drought treatment, the relative electrical conductivity of the root was higher than which grew in a normal condition and expressed significant difference at $3 \mathrm{~h}$. In contrast, the content of MDA declined from $0 \mathrm{~h}$ to $3 \mathrm{~h}$ in $\mathrm{CK}$ group, after that there was a slight increase. Moreover, the content of MDA at early stage $(1 \mathrm{~h})$ of drought treatment showed significantly higher than that in CK group and then went down sharply at $3 \mathrm{~h}$ and $7 \mathrm{~h}$.

Under environmental drought stress, reactive oxygen species (ROS) levels will increase dramatically, which results in oxidative damage to DNA, proteins and lipids (Apel and Hirt, 2004). They (such as $\mathrm{O}^{2}$ - and $\mathrm{H}_{2} \mathrm{O}_{2}$ ) will attack membrane lipids directly and increase lipid peroxidation (Mittler, 2002). The relative electrical conductivity (Wang et al., 2012) and the content of MDA is considered an indicator of oxidative damage (Moller et al., 2007) and MDA is thought to be a marker for membrane lipid peroxidation. Decreasing in membrane stability shows the level of lipid peroxidation that is caused by ROS. Moreover, in tissues, lipid peroxidation can indicate the prevalence of free radical reaction. Furthermore, oxygen uptake loading on the tissues will generate ROS in both processes (Anjum et al., 2011b). When faced with drought stress, many species showed an increase of MDA and relative electrical conductivity like Cucumis sativus L. (Wang et al., 2012), Nicotiana tabacum L. (Wang et al., 2006), Triticum aestivum L. (Hongbo et al., 2005), Phillyrea angustifolia L. (Munné-Bosch and Peñuelas, 2003) and so on. In our research, the content of MDA showed a significant risie at $1 \mathrm{~h}$ which means in a short time after drought treatment, there might be 
a lot of ROS produced rapidly and caused damage to proteins and lipids. But when it went to $3 \mathrm{~h}$ and $7 \mathrm{~h}$, the content of MDA in drought stress group decreased. This may because many proteins like antioxidase related to drought resistance in pearl millet were generated so that ROS were converted to non-harmful substance. Therefore, it showed a decline of MDA in later period. At the same time, the relative electrical conductivity rose gradually from $0 \mathrm{~h}$ to $7 \mathrm{~h}$ no matter in CK or treatment group but did not emerge a significant difference between $\mathrm{CK}$ and drought stress at $7 \mathrm{~h}$, which also suggests that there might be some substance that was produced to ease this situation.

a

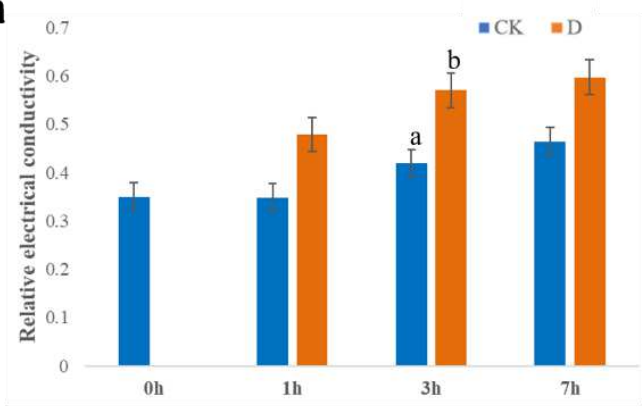

b

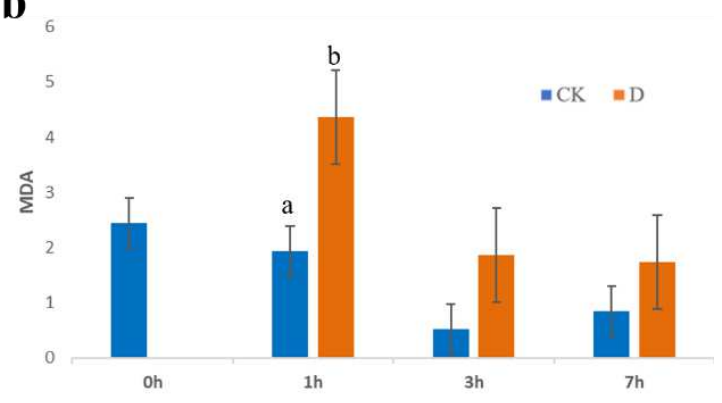

Figure 1. a. the relative conductivity at $0 \mathrm{~h}, 1 \mathrm{~h}, 3 \mathrm{~h}$ and $7 \mathrm{~h}$ of $\mathrm{CK}$ and drought group in root. $\mathbf{b}$. the content of MDA at $0 \mathrm{~h}, 1 \mathrm{~h}, 3 \mathrm{~h}$ and $7 \mathrm{~h}$ of $\mathrm{CK}$ and drought group in root.

\section{Data analysis of RNA-seq}

Total 16 qualified cDNA libraries were separately constructed and used to RNA-seq. The quality of RNA-seq was decided with the quality of sequencing and the correlations of biological replicates. In this study, the Q20 or Q30 exceeded 93\% and the percentage of GC was greater than 53\%. Furthermore, the FPKM values of 16 samples were assessed by Pearson correlation (R2) and Principal component analysis (PCA) (Supplemental figure 1). These results indicated that the quality of sequencing was high. Overall, the data of RNA-seq is reliable and can be used to perform the later analysis.

\section{Analysis of DEGs among drought stress and control conditions}

In order to determine the DEGs involving in response of drought stress, three comparisons (total DEGs of three time points, up-regulated DEGs of three time points and down- regulated DEGs of three time points) were performed with a threshold of $\mid \log _{2}$ (FC) $\mid \geq 1$ and $\mathrm{P}$ value $\leq 0.05$ (Figure 2). There were 2004 (1364 up-regulated and 640 down-regulated), 1538 (676 up-regulated and 862 down-regulated) and 605 (449 up-regulated and 156 down-regulated) genes that showed different expression after 1, 3 and $7 \mathrm{~h}$ drought treatment respectively (Figure 2a). Besides, 12 DEGs showed up-regulated at all three time points while 2 DEGs showed the opposite trend at all three time points. On the other hand, 1655, 1189 and 389 genes expressed specifically at $1 \mathrm{~h}, 3 \mathrm{~h}$ and $7 \mathrm{~h}$ drought stress respectively which took large proportions (Figure 2b). With drought time extension, the number of DEGs went down.

The number of DEGs decreased from $1 \mathrm{~h}$ to $7 \mathrm{~h}$, which had the same trend with the content of MDA under drought stress. This indicates that at the beginning of drought stress, although plenty of ROS were produced, the pearl millet could react to it rapidly due to its strong drought resistance. Lots of genes were expressed and brought in many proteins such as enzymes to respond to the sudden shock and after that, 
cells went back to a relative balance level. It could be a signal for plants that they were in a normal condition so in a short time, it was not essential to express lots of genes but just growth normally. This phenomenon also appeared in Zea mays L. (Zhang et al., 2019). Both drought tolerant cultivar and drought sensitive cultivar maize were faced with drought stress at seedling stage, the number of DEGs in primary roots at $12 \mathrm{~h}$ was less than that at oh. In our research, 12 and 2 genes exhibited up- and downregulated at all three time points, which may illustrate they play some important roles in response related to drought stress. These genes should be targets of later study.

a

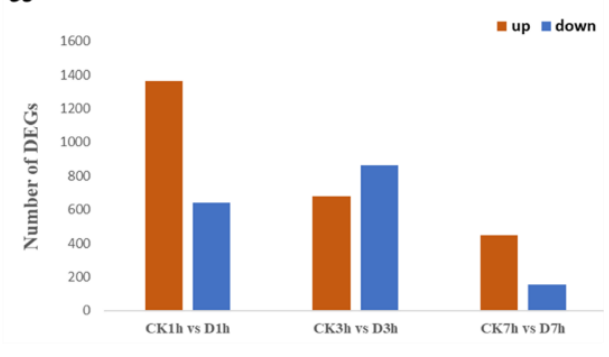

c

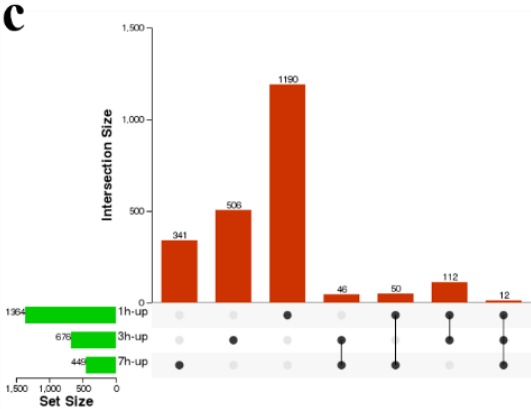

b

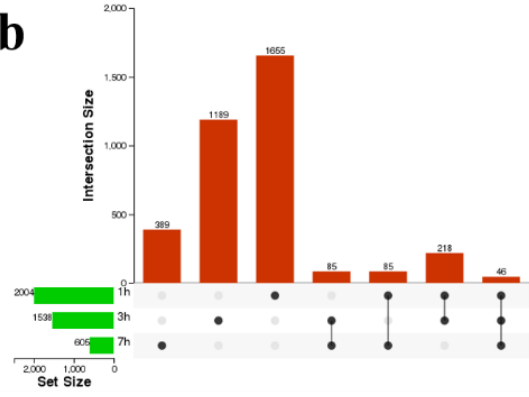

d

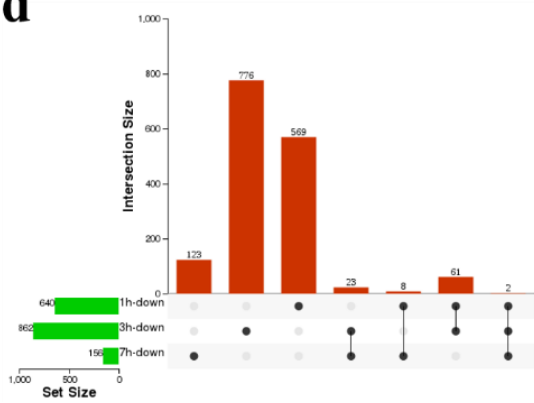

Figure 2. a. The number of DEGs between CK and drought stress group at $1 \mathrm{~h}, 3 \mathrm{~h}$ and $7 \mathrm{~h}$. b, $\mathbf{c}, \mathbf{d}$. DEGs of setup diagram at $1 \mathrm{~h}, 3 \mathrm{~h}$ and $7 \mathrm{~h}$ time points.

\section{DEGs analysis of GO and KEGG pathway}

Annotation and analysis of GO cluster of DEGs at three time points were performed. Most of DEGs in each time point were different to that in other time points, but the top five GO terms of three categories which they clustered were nearly the same (Figure 3). In the 'Biological process' category, larger genes were clustered in 'metabolic process', 'cellular process', 'single-organism process', 'localization' and 'biological regulation' (Figure 3a). Fewer genes clustered in 'Cellular component' than that in 'Biological process' and 'Molecular function' and top five number of genes in $3 \mathrm{~h}$ and 7h were related to 'membrane', 'cell', 'cell part', 'membrane part' and 'macromolecular complex', while for $1 \mathrm{~h}$, there is no 'macromolecular complex' but 'organelle' (Figure 3c). In the 'Molecular function' category, DEGs annotated as 'catalytic activity', 'binding' and 'transporter activity' were clustered most (Figure 3e). At $1 \mathrm{~h}$ and $7 \mathrm{~h}$ after drought treatment, it was obvious that up-regulated genes were more than down-regulated genes no matter in which category and the situation was totally opposite to DEGs at $3 \mathrm{~h}$ after drought stress.

At the same time, DEGs in each time point were also performed with analysis of KEGG function (Figure 3). At 1h, DEGs were clustered into 'MAPK signaling pathway - plant', 'Plant hormone 
signal transduction' and 'Galactose metabolism' pathways significantly (Figure 3b). When it comes to $3 \mathrm{~h}$ after drought treatment, DEGs were clustered into 13 pathways significantly and they are 'Taurine and hypotaurine metabolism', 'Cysteine and methionine metabolism', 'Glycolysis / Gluconeogenesis', 'Nitrogen metabolism', 'Alanine, aspartate and glutamate metabolism', 'Biosynthesis of secondary metabolites', 'Pentose phosphate pathway', 'Metabolic pathways', 'Glutathione metabolism', 'Tyrosine metabolism', 'Arginine biosynthesis' and 'Fatty acid degradation' (Figure 3d), which has much variation from that in $1 \mathrm{~h}$. And there were just two pathways ('Taurine and hypotaurine metabolism 'and 'Biosynthesis of amino acids') where DEGs clustered significantly after 7 hours drought stress (Figure 3f).
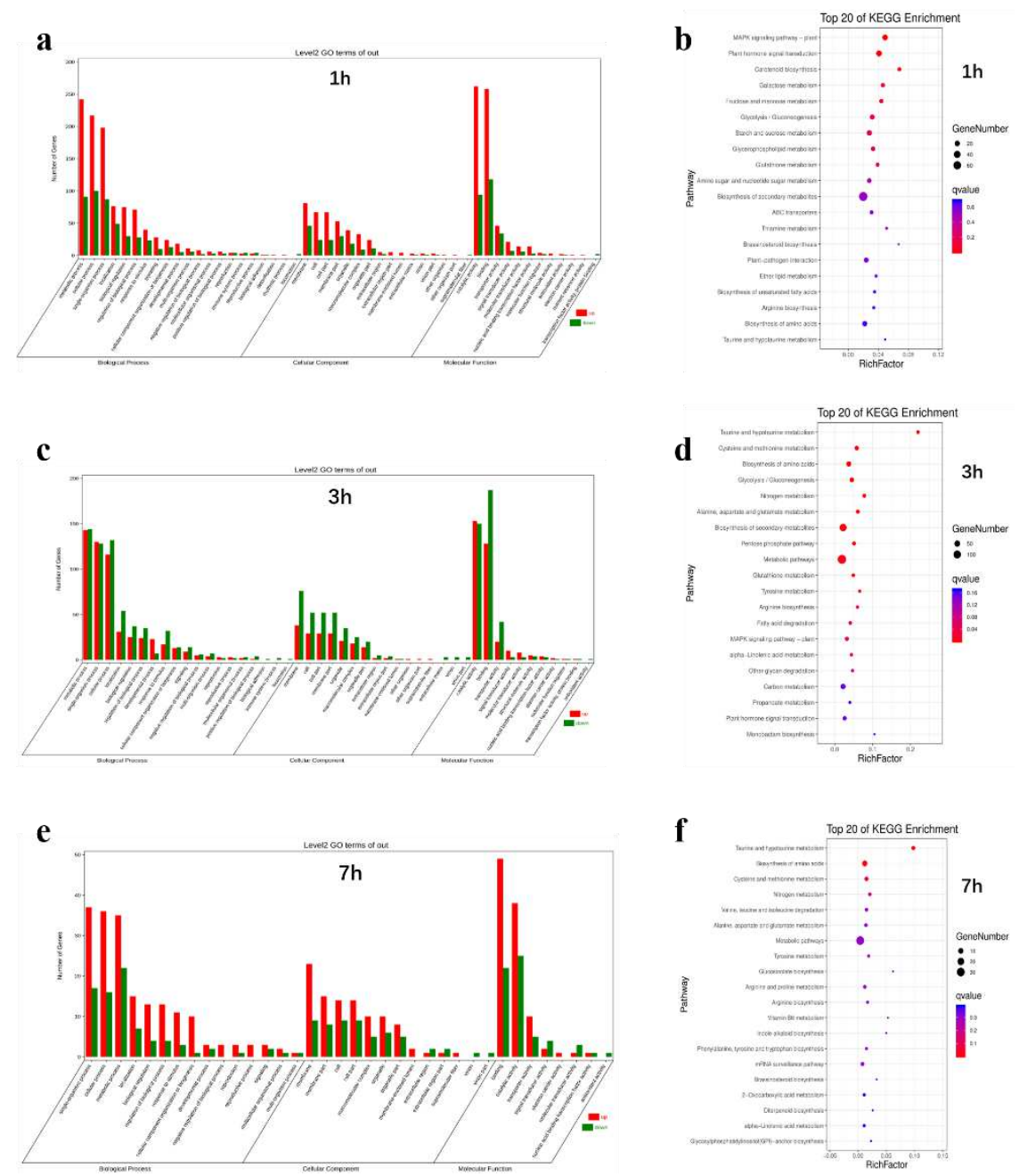

Figure 3. Analysis of DEGs expressing differently between CK and drought stress. a, c, e. GO analysis of DEGs specific to drought stress at $1 \mathrm{~h}, 3 \mathrm{~h}$ and $7 \mathrm{~h}$. b, d, f. KEGG analysis of DEGs specific to drought stress at $1 \mathrm{~h}, 3 \mathrm{~h}$ and $7 \mathrm{~h}$.

Plants can cope with drought stress through manipulating some key physiological processes like respiration, antioxidant and hormonal metabolism (Bhargava et al., 2013). In enrichment analysis of GO term on 'Biological process', most DEGs were clustered into metabolic processes significantly. Respiration being a very crucial metabolic way plays necessary roles in drought response. The rate of respiration is regulated by processes that use the respiratory products such as ATP, NADH and TCA cycle intermediates, which contribute to plant growth together. Under 
drought stress, these processes will be affected and lead to a decline in respiration rate. On the other hand, higher respiration may arise because of oxidative phosphorylation, reducing the generation of ROS and preventing the accumulation of reductants. Besides, activation of energy-intensive processes and increased respiratory rates like osmolyte synthesis and antioxidant metabolism occurring under drought conditions (Florez-Sarasa et al., 2010; Lambers and Ribas-Carbó, 2005). Under drought treatment, ROS are generated due to metabolic perturbation of cells, and these cause cell damage and death (Carvalho, 2008; Nxele et al., 2017; Uzilday et al., 2012). A very important adaptive mechanism involves their effective scavenging. And when these harmful substances do arise, antioxidant substrates like carotenoids, ascorbate as well as a-tocopherol and antioxidant enzymes like SOD (superoxide dismutase), CAT (catalase), APX (ascorbate peroxidase) and glutathione reductase exist in cell organelles and the cytoplasm and play a crucial role in detoxifying these reactive species (Shao et al., 2008). These important antioxidant enzymes were produced by some metabolic process so when suffering a shock of drought stress, huge metabolic related genes need to be expressed at a high level to respond to drought especially in drought tolerance species like pearl millet. Furthermore, lots of DEGs were clustered into 'membrane' in 'Cellular component'. This may because ROS will attack membranes of cells, and plants try to express related genes to repair it. And in this process, transcription factors (TFs) are also very essential. TFs act as switches and trigger the expression of a huge number of stress-response genes that contribute to the stress phenotype (Bartels and Souer, 2003). Up to now, many TFs were identified related to drought resistance belonging to bHLH, bZIP, HD-ZIP, AP2/ERF, MYB, EAR, NAC, NF-Y and ZPT2 families (Bhargava et al., 2013). These TFs can bind with some specific sites or target genes and then regulate them. In our research, there were a large number of DEGs clustered into 'binding', which may be due to the need of binding events between TFs and their important targets.

When treated with drought stress, signal transduction in plants is very eventful. Mitogen-activated protein kinases (MAPK) bring about protein phosphorylation constituting one of the main mechanisms of signal transduction in plants. Located in the cytoplasm, they consist of three types of enzymes (MAPK, MAPKK and MAPKKK), which form a signaling cascade from the stress sensor located on the plasma membrane to the regulation of gene expression in the nucleus. Transferring of the MAPK to the nucleus gives rise to the activation of transcription factors through phosphorylation (Bhargava et al., 2013; Tena et al., 2001). In our study, lots of genes gathered into the 'MAPK signaling pathway- plant' of KEGG enrichment analysis at $1 \mathrm{~h}$ and $3 \mathrm{~h}$. This result showed that pearl millet responded to drought environment positively by much signal transduction. At same time, we can find that there were not many DEGs clustered into 'MAPK signaling pathwayplant'. This may be because as we discussed earlier, after drought shock, huge numbers of genes were highly expressed and generated proteins to contain the balance of cells by a series biochemical reaction. And then there was no need for so many genes to express in a relative steady state.

Phytohormones are central factors in sensing and signaling various environmental conditions like drought stress (Ollas et al., 2013). When exposed to water deficits, ABA will be synthesized in roots and translocated to leaves, where it leads stomatal closure so that enable the plant to adapt to drought environment (Wilkinson and Davies, 2010). Many researches (Fujita et al., 2005; Seiler et al., 2011; Zhang et al., 2006) indicated that biosynthesis of ABA was related to drought response. Cytokinins are a kind of negative regulating factor of root growth and branching. Root-specific degradation of cytokinin could make contribution of primary root growth and branching, which were induced by 
drought stress, so that to increase drought tolerance in Arabidopsis (Werner et al., 2010). Jasmonic acid (JA) and its metabolites, collectively known as jasmonates, originating from lipid oxidation pathways Jasmonate signaling are associated with stress responses including defense responses against biotic stressors such as pathogens and insects and also responses to abiotic stresses. (Ollas et al., 2013).

\section{Weighted gene co-expression network analysis.}

The co-expression network of candidate DEGs was made through WGCNA. According to pairwise correlations and gene expression trends among all samples, co-expression networks were constructed using normalized microarray expression data of all DEGs from all samples using the WGCNA R package. DEGs were clustered into 13 modules (lightgreen, green, purple, brown, blue, tan, grey60, black, magenta, yellow, pink, cyan and lightcyan) with high correlation values (Figure $4 \mathrm{~b})$ and DEGS that couldn't gather into modules would be abandoned. Notably, the MEblue (0.99), MEblack (0.85) as well as MEmagenta (0.78) and MEpurple (0.72) as well as brown (0.74) modules were highly correlated with drought for $1 \mathrm{~h}, 3 \mathrm{~h}$ and $7 \mathrm{~h}$ respectively. In addition, sample clustering was also performed through their gene expression (Figure 4a).

Furthermore, DEGs in three modules that were the highest correlation with drought in each time point after drought treatment were analyzed through KEGG pathway analysis (Figure 4). The number of DEGs in the module (MEblue) which had the highest correlation to drought stress for $1 \mathrm{~h}$ was 388 and they were clustered in 'Glycolysis / Gluconeogenesis', 'Biosynthesis of secondary metabolites', 'Carotenoid biosynthesis', 'Glutathione metabolism', 'Fructose and mannose metabolism', 'Biosynthesis of amino acids', 'Plant hormone signal transduction' and 'alphaLinolenic acid metabolism' pathways significantly (Figure 4b) and DEGs correlated to 3 hours' drought stress (80) clustered into only one pathway ('Galactose metabolism') significantly(Figure 4c). 'Circadian rhythm - plant' and 'Flavonoid biosynthesis' were two pathways which DEGs related to 7 hours' water deficit (113) clustered into significantly (Figure 4d). 
a

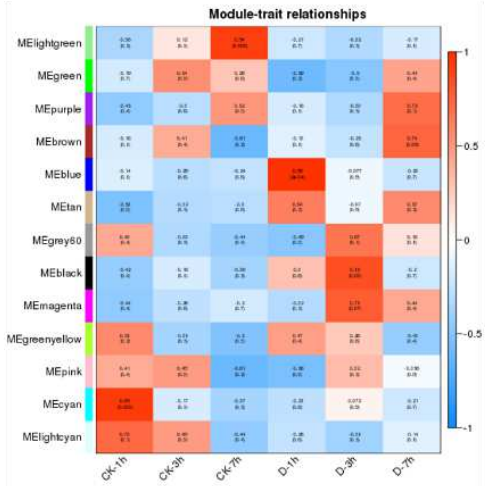

c

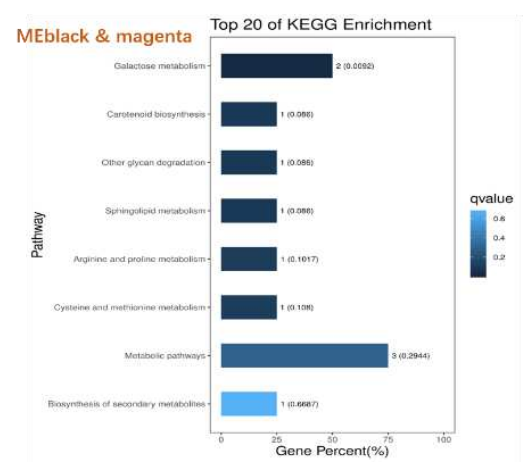

b

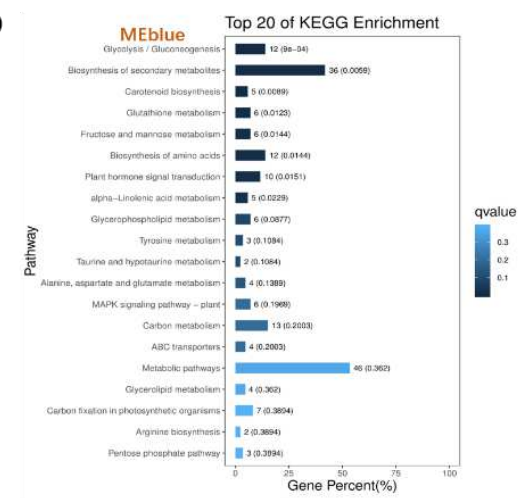

d

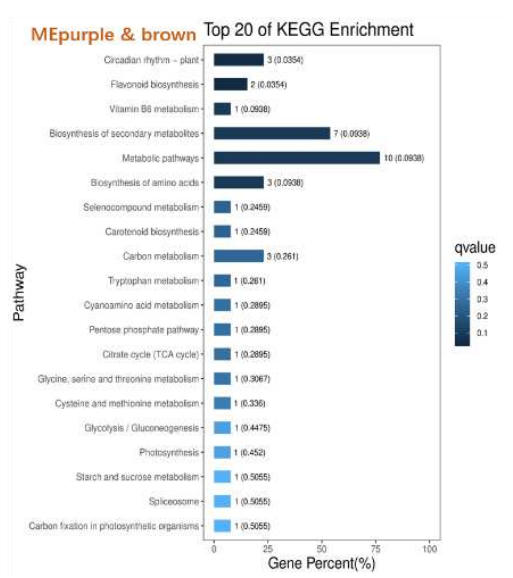

Figure 4 a. A weighted correlation network analysis of genes at 6 groups. b. KEGG analysis of MEblue module. c. KEGG analysis of MEblack and MEmagenta. d. KEGG analysis of MEpurple and MEbrown.

As we can see, some DEGs related to $1 \mathrm{~h}$ drought stress (MEblue) were clustered into 'Plant hormone signal transduction' and 'MAPK signaling pathway-plant' pathways significantly while not shown at $3 \mathrm{~h}$ and $7 \mathrm{~h}$. Both two pathways were identified related to stress response (Bartels and Souer, 2003; Ollas et al., 2013; Tena et al., 2001). These results suggested that after $1 \mathrm{~h}$ of drought stress or even earlier than $1 \mathrm{~h}$, some important genes began to play roles in drought tolerance in the root of pearl millet through a series of Biochemical reactions. This process provided a certain degree of effect for cells to maintain homeostasis in a short period of time, which is consistent with the result of the whole article.

\section{ABA signaling pathway}

19 genes were found to participate in the ABA signaling pathway to respond to drought stress. A total of 11 PP2C-type protein phosphatases (PP2C) genes showed differently expression under drought stress in pearl millet at $1 \mathrm{~h}$ while there was one that had no difference between $\mathrm{CK}$ and drought stress group but went up under drought stress at $3 \mathrm{~h}$ and restored to same as that in $\mathrm{CK}$ at $7 \mathrm{~h}$. When it came to $3 \mathrm{~h}, 4$ out of 11 genes were still over expressed under drought compared to CK. However, all these 12 genes went down to the CK levels at 7h. Besides, 2 SnRK2-type protein kinases (SnRK2s) showing an up-regulated expression in ABA signal transduction pathway at $3 \mathrm{~h}$ under water deficit environment but had the same situation with $\mathrm{CK}$ at $1 \mathrm{~h}$ and $7 \mathrm{~h}$ (Figure 5). 
The ABA signaling components are implicated in the regulation of guard cell ion channels (Pei et al., 1997). Studies showed that pyrabactin resistance (PYR)-like (PYL) family could be bind directly with $\mathrm{ABA}$ function as receptors although many other gene families like regulatory component of ABA receptor (RCAR) family were also been identified to be ABA receptors (Jacques et al., 1998; Kitahata et al., 2005; Ma et al., 2009; Park et al., 2009). PYL/PYR family also have been shown to connect with the other ABA regulators like the PP2C SnRK2 (Lee and Luan, 2011) and directly inhibit phosphatase activity of PP2Cs (Szostkiewicz et al., 2010). Besides, genetic evidence revealed that PP2Cs are negative regulators of ABA signaling (Gosti et al., 1999; Merlot et al., 2010; Wasilewska et al., 2008). Many studies have proved several SnRK2-PP2C interactions that function in ABA signaling clearly (Yoshida et al., 2006). For example, the interaction of A-type PP2Cs with OST1 (one of SnRK2-type kinases) contributed to ABA-induced stomatal closure by controlling phosphorylation status and activity of the SLAC1 anion channel in guard cells (Lee et al., 2009) and the activation of SnRK2-type kinases (ABA-dependent) results from removal of the inhibitory effect of PP2Cs (Hubbard et al., 2010). This can be realized by the binding of PYL/RCARs with the PP2Cs, leading to activation of SnRKs and de-repression of the signaling pathway (Fujii et al., 2009; Lee and Luan, 2011; Ma et al., 2009; Park et al., 2009). Overall, in response to drought or other stresses, the content of ABA will be up-regulated to reach certain level so that to bind to PYL/RCAR-type receptors and improve the interaction between PYL/ RCAR and PP2Cs, which can activate SnRK2s in turn interact with and phosphorylate SLAC1 and other channels leading to stomatal closure (Lee et al., 2009; Pei et al., 1997). In this study, we could find there were no PYP/PYL genes expressing differently between $\mathrm{CK}$ and drought group, but PP2C genes had higher expression under drought. This may be because PYP/PYL genes had finished their drought response before the sample collection time point (1h) and they went back to a normal status just as we mentioned before. And in this situation, those PYP/PYL proteins still existed in the cell and stimulated the expression of PP2Cs, which inhibited the SnRK2 (1h). As time went to 7h, low ABA levels lead to the release of PYP/PYL, so the expression of PP2C was suppressed, which caused improvement of SnRK2. From this way, they contributed to stomatal closure, enhancing the drought tolerance of pearl millet.

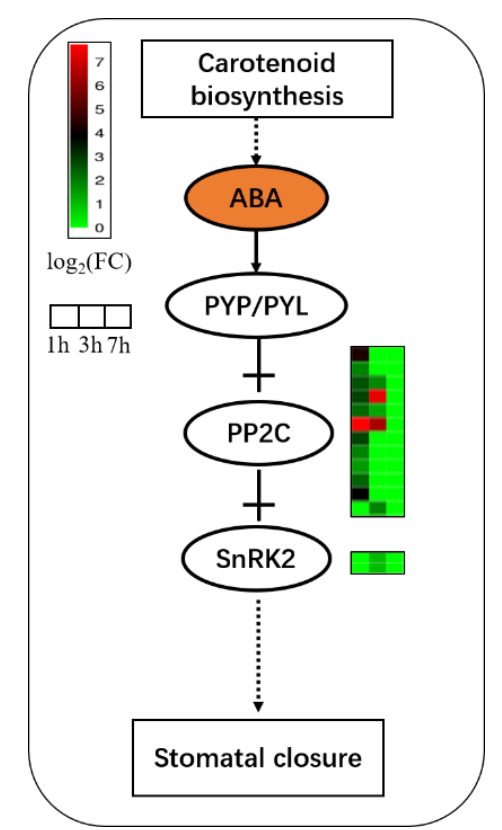

Figure 5. ABA signaling transduction pathway. Heatmaps represent the $\log _{2}(\mathrm{FC})$ of genes at the corresponding time points. 
According to the results, we thought some earlier time points should be laid out because even at $1 \mathrm{~h}$, pearl millet has showed the drought resistance in root at transcriptome level, which should be a later research target since some important genes may only show regulation role in drought tolerance at a earlier stage (earlier that 1 hour).

\section{Conlusion}

In this study, we tested the physiological intex (relative electrical conductivity and MDA) of the root of pearl millet at $0 \mathrm{~h}, 1 \mathrm{~h}, 3 \mathrm{~h}$ and $7 \mathrm{~h}$. The results showed that they had up and down trends respectively, which indicated that pearl millet could take a rapid response to drought stress. At the same time, according to the analysis of transcriptome, we found that the number of DEGs went down from $1 \mathrm{~h}$ to $7 \mathrm{~h}$, which had a similar trend with the change of MDA content. Besides, DEGs at $1 \mathrm{~h}$ were clustered into 'metabolic processes', 'MAPK signaling pathway' and 'plant hormone signal transduction', which has been reported to be related to drought response. These results suggested that pearl millet could return to steady state after a short time drought treatment because of some change of gene expression as well as physiological and biochemical changes. Furthermore, some genes participating in ABA signal transduction pathway like PP2C and SnRK2 were found to have changes in exprssion level, especially differently expressed at $1 \mathrm{~h}$ and $3 \mathrm{~h}$, indicating that pearl millet might take actions to response drought stress before $1 \mathrm{~h}$ and $\mathrm{ABA}$ signal transduction pathway played an important role in drought tolerance in pearl millet. This study can provide a theoretical basis to enhance drought resistance in other plants.

\section{Declarations}

\section{Ethics approval and consent to participate}

Not applicable.

\section{Consent for publication}

Not applicable.

\section{Availability of data and materials}

The datasets supporting the conclusions of this article are included within the article (and its supplemental files). RNA-seq database for pearl millet could download from NCBI under the accession number XXXXXXXXX, and the data will be shared on reasonable request of the corresponding author.

\section{Competing interests}

The authors declared that they have no conflicts of interest to this work.

\section{Authors' contributions}

Ailing Zhang, Yang Ji, Min Sun, Chuang Lin and Dan Luo participated in material processing and transcriptome data analysis. Puding Zhou and Juncai Ren provided bioinformatics support. Dan Luo, Xiaoshan Wang and Encong Ma revised the paper. Linkai Huang designed the research, provided supervision and contributed to the manuscript. All authors read and approved the final manuscript.

\section{Funding}

This work was supported by the Sichuan Province Research Grant (2016NYZ0036), the Modern 
Agro-industry Technology Research System (CARS-34), College Students' Innovation and Entrepreneurship Training Program and the Modern Agricultural Industry System Sichuan Forage Innovation Team (SCCXTD-2020-16).

\section{Reference}

Adebayo, M.A., and Menkir, A. (2015). Assessment of hybrids of drought tolerant maize (Zea mays L.) inbred lines for grain yield and other traits under stress managed conditions. Nigerian Journal of Genetics, https://doi.org/10.1016/j.nigjg.2015.1006.1004.

Adee, E., Roozeboom, K., Balboa, G.R., Schlegel, A., and Ciampitti, I.A. (2016). Drought-Tolerant Corn Hybrids Yield More in Drought-Stressed Environments with No Penalty in Non-stressed Environments. Frontiers in Plant Science, http://doi.org/10.3389/fpls.2016.01534

Ambika, D., Harshraj, S., Daisuke, T., Shenkui, L., Tetsuo, T., and Singh, Y.R. (2018). Transcriptomic analysis reveals the differentially expressed genes and pathways involved in drought tolerance in pearl millet [Pennisetum glaucum (L.) R. Br]. Plos One, http://doi.org/10.1371/journal.pone.0195908.

Amir, M., Rahim, N., and Reza, S. (2011). Response of Different Growth Stages of Wheat to Moisture Tension in a Semiarid Land. World Applied Sciences Journal 12, 83-89.

Andrews, D.J., and Kumar, K.A. (1992). Pearl Millet for Food, Feed, and Forage. Advances in Agronomy, http://doi.org/10.1016/S0065-2113(1008)60936-60930

Anjum, S.A., XiE, X.Y., L C. Wang, Saleem, M., Chen, M., and Wang, L. (2011a). Morphological, physiological and biochemical responses of plants to drought stress. Conference Proceedings, http://doi.org/10.5897/AJAR5810.5027.

Anjum, S.A., Xie, X.Y., Wang, L.C., Saleem, M.F., and Lei, W. (2011b). Morphological, physiological and biochemical responses of plants to drought stress. African Journal of Agricultural Research, http://doi.org/10.5897/AJAR5810.5027.

Apel, K., and Hirt, H. (2004). REACTIVE OXYGEN SPECIES: Metabolism, Oxidative Stress, and Signal Transduction. Annu Rev Plant Bio, http://doi.org/doi10.1146/annurev.arplant.1155.031903.141701.

Awan, S.A., Khan, I., Rizwan, M., Zhang, X., Brestic, M., Khan, A., El-Sheikh, M.A., Alyemeni, M.N., Ali, S., and Huang, L. (2020). Exogenous abscisic acid and jasmonic acid restrain PEG-induced drought by improving the growth and antioxidative enzyme activities in pearl millet. Physiologia Plantarum, http://doi.org/10.1111/ppl.13247.

Bartels, D., and Souer, E. (2003). Molecular responses of higher plants to dehydration. Plant Responses to Abiotic Stress, http://doi.org/10.1007/1978-1003-1540-39402-39400_39402.

Bernier, J., Kumar, A., Ramaiah, V., Spaner, D., and Atlin, G. (2007). A Large-Effect QTL for Grain Yield under Reproductive-Stage Drought Stress in Upland Rice. Crop Science, http://doi.org/10.2135/cropsci2006.2107.0495

Bertin, C., Yang, X., and Weston, L.A. (2003). The role of root exudates and allelochemicals in the rhizosphere. Plant \& Soil, http://doi.org/10.1023/A:1026290508166.

Bhargava, S., Sawant, K., and Tuberosa, R. (2013). Drought stress adaptation: metabolic adjustment and regulation of gene expression. Plant Breeding, http://doi.org/10.1111/pbr.12004.

Carvalho, M.H.C.D. (2008). Drought stress and reactive oxygen species: Production, scavenging and signaling. Plant signaling \& behavior, http://doi.org/10.4161/psb.4163.4163.5536.

Chen, P., Chen, J., and Sun, M. (2020). Comparative transcriptome study of switchgrass (Panicum virgatum L.) homologous autopolyploid and its parental amphidiploid responding to consistent 
drought stress. Biotechnol Biofuels, https://doi.org/10.1186/s13068-13020-01810-z.

Choudhary, M., Jayanand, and Padaria, J.C. (2015). Transcriptional profiling in pearl millet (Pennisetum glaucum L.R. Br.) for identification of differentially expressed drought responsive genes. Physiology \& Molecular Biology of Plants An International Journal of Functional Plant Biology, http://doi.org/10.1007/s12298-12015-10287-12291

Dai, and Aiguo (2013). Increasing drought under global warming in observations and models. Nature Climate Change, http://doi.org/10.1038/nclimate1811

Dan, X., Wang, C., Su, Y., Zhang, A., and Huang, L. (2020). Evaluation of genetic integrity of pearl millet seeds during aging by genomic-SSR markers. Molecular Biology Reports, http://doi.org/10.1007/s11033-11020-05642-w.

Daryanto, S., Wang, L., and Jacinthe, P.A. (2016). Global Synthesis of Drought Effects on Maize and Wheat Production. http://doi.org/10.1371/journal.pone.0156362

Dennis, B.E., and Bruening, W.P. (2000). Potential of Early-Maturing Soybean Cultivars in Late Plantings. Agronomy Journal, http://doi.org/10.2134/agronj2000.923532x.

Dixit, S., Singh, A., Sta Cruz, M., Maturan, P.T., Amante, M., and Kumar, A. (2014). Multiple major QTL lead to stable yield performance of rice cultivars across varying drought intensities. Bmc Genetics, http://doi.org/10.1186/1471-2156-1115-1116.

Dixit, S., Swamy, B., Vikram, P., Ahmed, H., Sta Cruz, M., Amante, M., Atri, D., Leung, H., and Kumar, A. (2012). Fine mapping of QTLs for rice grain yield under drought reveals sub-QTLs conferring a response to variable drought severities. Theoretical \& Applied Genetics, http://doi.org/10.1007/s00122-00012-01823-00129.

Farooq, M., Basra, S.M.A., Wahid, A., Ahmad, N., and Saleem, B.A. (2009). Improving the Drought Tolerance in Rice (Oryza sativa L.) by Exogenous Application of Salicylic Acid. Journal of Agronomy \& Crop Science, http://doi.org/10.1111/j.1439-1037X.2009.00365.x

Feng, S., and Fu, Q. (2013). Expansion of global drylands under a warming climate. Atmospheric chemistry and physic, http://doi.org/10.5194/acp-5113-10081-12013

Florez-Sarasa, I.D., Bouma, T.J., Medrano, H., Azcon-Bieto, J., and Ribas-Carbo, M. (2010). Contribution of the cytochrome and alternative pathways to grown respiration and maintenance respiration in Arabidopsis thaliana. Physiologia Plantarum, http://doi.org/10.1111/j.13993054.2006.00796.x.

Fujii, Hiroaki, and Zhu, J.K. (2009). Arabidopsis mutant deficient in 3 abscisic acid-activated protein kinases reveals critical roles in growth, reproduction, and stress. Proceedings of the National Academy of Sciences of the United States of America, http://doi.org/10.1073/pnas.0903144106.

Fujita, Y., Fujita, M., Satoh, R., Maruyama, K., Parvez, M.M., Seki, M., Hiratsu, K., Ohme-Takagi, M., Shinozaki, K., and Yamaguchi-Shinozaki, K. (2005). AREB1 Is a Transcription Activator of Novel ABRE-Dependent ABA Signaling That Enhances Drought Stress Tolerance in $<$ em $>$ Arabidopsis $</$ em>. The Plant Cell, http://doi.org/10.1105/tpc.1105.035659.

Ghimire, K.H., Quiatchon, L.A., Vikram, P., Swamy, B.P.M., Dixit, S., Ahmed, H., Hernandez, J.E., Borromeo, T.H., and Kumar, A. (2012). Identification and mapping of a QTL (qDTY1.1) with a consistent effect on grain yield under drought. Field crops research, http://doi.org/10.1016/j.fcr.2012.1002.1028

Gosti, F., Beaudoin, N., Serizet, C., Webb, A., Vartanian, N., and Giraudat, J. (1999). ABI1 protein phosphatase $2 \mathrm{C}$ is a negative regulator of abscisic acid signaling. Plant Cell, http://doi.org/10.1105/tpc.1111.1110.1897. 
Hongbo, S., Zongsuo, L., and Mingan, S. (2005). Changes of anti-oxidative enzymes and MDA content under soil water deficits among 10 wheat (Triticum aestivum L.) genotypes at maturation stage. Colloids \& Surfaces B Biointerfaces, http://doi.org/10.1016/j.colsurfb.2005.1006.1016.

Huang, B., and Fry, J.D. (1998). Root Anatomical, Physiological, and Morphological Responses to Drought Stress for Tall Fescue Cultivars. Crop ence, http://doi.org/10.2135/cropsci1998.0011183X003800040022x.

Hubbard, K.E., Nishimura, N., Hitomi, K., Getzoff, E.D., and Schroeder, J.I. (2010). Early abscisic acid signal transduction mechanisms: newly discovered components and newly emerging questions. Genes Dev, http://doi.org/10.1101/gad.1953910.

Jacques, Pedron, Mathias, Brault, Christian, Nake, Emile, and Miginiac (1998). Detection of abscisicacid-binding proteins in the microsomal protein fraction of Arabidopsis thaliana with abscisic-acidprotein conjugates used as affinity probes. European Journal of Biochemistry, http://doi.org/10.1046/j.1432-1327.1998.2520385.x.

Ji, Y., Chen, P., Chen, J., Pennerman, K., Liang, X., Yan, H., Zhou, S., Feng, G., Wang, C., and Yin, G. (2018a). Combinations of Small RNA, RNA, and Degradome Sequencing Uncovers the Expression Pattern of microRNA-mRNA Pairs Adapting to Drought Stress in Leaf and Root of Dactylis glomerata L. International Journal of Molecular Sciences, http://doi.org/10.3390/ijms19103114.

Ji, Y., Chen, P., Chen, J., Pennerman, K., Liang, X., Yan, H., Zhou, S., Feng, G., Wang, C., Yin, G., et al. (2018b). Combinations of Small RNA, RNA, and Degradome Sequencing Uncovers the Expression Pattern of microRNA ${ }^{-}$mRNA Pairs Adapting to Drought Stress in Leaf and Root of Dactylis glomerata L. Int J Mol Sci, http://doi.org/10.3390/ijms19103114.

Khan, I., Awan, S., Raza, M., Rizwan, M., Tariq, R., Ali, S., and Huang, L. (2020a). Silver nanoparticles improved the plant growth and reduced the sodium and chlorine accumulation in pearl millet: a life cycle study. Environ Sci Pollut Res Int, http://doi.org/10.1007/s11356-11020-11612-11353.

Khan, I., Raza, M.A., Awan, S.A., Khalid, M.H.B., and Huang, L. (2019a). In vitro effect of metallic silver nanoparticles (agnps): a novel approach toward the feasible production of biomass and natural antioxidants in pearl millet (Pennisetum glaucum L.). Applied Ecology and Environmental Research, http://doi.org/10.15666/aeer/11706_1287712892.

Khan, I., Raza, M.A., Awan, S.A., Shah, G.A., Rizwan, M., Ali, B., Tariq, R., Hassan, M.J., Alyemeni, M.N., and Brestic, M. (2020b). Amelioration of salt induced toxicity in pearl millet by seed priming with silver nanoparticles (AgNPs): The oxidative damage, antioxidant enzymes and ions uptake are major determinants of salt tolerant capacity. Plant Physiology and Biochemistry, http://doi.org/10.1016/j.plaphy.2020.1009.1018.

Khan, I., Raza, M.A., Khalid, M.H.B., Awan, S.A., Raja, N.I., Zhang, X., Min, S., Wu, B.C., Hassan, M.J., and Huang, L. (2019b). Physiological and Biochemical Responses of Pearl Millet (Pennisetum glaucum L.) Seedlings Exposed to Silver Nitrate (AgNO3) and Silver Nanoparticles (AgNPs). International Journal of Environmental Research and Public Health, http://doi.org/10.3390/ijerph16132261.

Kitahata, N., Nakano, T., Kuchitsu, K., Yoshida, S., and Asami, T. (2005). Biotin-labeled abscisic acid as a probe for investigating abscisic acid binding sites on plasma membranes of barley aleurone protoplasts. Bioorganic \& Medicinal Chemistry, http://doi.org/10.1016/j.bmc.2005.1003.1017.

Lambers, H., Chapin, F., and Pons, T. (2008). Plant physiological ecology, 2nd edn. Springer, New York, http://doi.org/10.1093/aob/mcn1225.

Lambers, H., and Ribas-Carbó, M. (2005). Plant Respiration. From Cell to Ecosystem. loan/open shelves, 
http://doi.org/10.1007/1001-4020-3589-1006.

Langfelder, P., and Horvath, S. (2008). WGCNA: an R package for weighted correlation network analysis. BMC bioinformatics 9, 559.

Lee, S., Lan, W., Buchanan, B., and Luan, S. (2009). A protein kinase-phosphatase pair interacts with an ion channel to regulate ABA signaling in plant guard cells. Proc Natl Acad Sci USA, http://doi.org/10.1073/pnas.0910601106.

Lee, S.C., and Luan, S. (2011). ABA signal transduction at the crossroad of biotic and abiotic stress responses. Plant Cell \& Environment, http://doi.org/10.1111/j.1365-3040.2011.02426.x.

Li, B., and Dewey, C. (2011). RSEM: accurate transcript quantification from RNA-Seq data with or without a reference genome. BMC Bioinformatics, http://doi.org/10.1186/1471-2105-1112-1323.

Li, B., Ruotti, V., Stewart, R.M., Thomson, J.A., and Dewey, C.N. (2009a). RNA-Seq gene expression estimation with read mapping uncertainty. Bioinformatics, http://doi.org/10.1093/bioinformatics/btp1692.

Li, Y.P., Wei, Y., Meng, W., and Yan, X.D. (2009b). Climate change and drought: A risk assessment of crop-yield impacts. Climate Research, http://doi.org/10.3354/cr00797

Lin, Y., Zhang, A., Yang, S., and Huang, L. (2019). Reference gene selection for real-time quantitative PCR normalization in Hemarthria compressa and Hemarthria altissima leaf tissue. Molecular Biology Reports, http://doi.org/10.1007/s11033-11019-04922-11034.

Ma, Y., Szostkiewicz, I., Korte, A., Moes, D., Yang, Y., Christmann, A., and Grill, E. (2009). Regulators of PP2C phosphatase activity function as abscisic acid sensors. Science, http://doi.org/10.1126/science.1172408.

Manivannan, P., Jaleel, C.A., Somasundaram, R., and Panneerselvam, R. (2008). Osmoregulation and antioxidant metabolism in drought-stressed Helianthus annuus under triadimefon drenching. Comptes Rendus Biologies, http://doi.org/10.1016/j.crvi.2008.1003.1003.

Merlot, S., Gosti, F., Guerrier, D., Vavasseur, A., and Giraudat, J. (2010). The ABI1 and ABI2 protein phosphatases $2 \mathrm{C}$ act in a negative feedback regulatory loop of the abscisic acid signalling pathway. Plant Journal, http://doi.org/10.1046/j.1365-1313x.2001.00965.x.

Mishra, R.N., Reddy, P.S., Nair, S., Markandeya, G., Reddy, A.R., Sopory, S.K., and Reddy, M.K. (2007). Isolation and characterization of expressed sequence tags (ESTs) from subtracted cDNA libraries ofPennisetum glaucumseedlings. http://doi.org/10.1007/s11103-11007-19193-11104

Mittler, R. (2002). Oxidative stress, antioxidants and stress tolerance. Trends in Plant Science, http://doi.org/10.1016/S1360-1385(1002)02312-02319.

Munné-Bosch, S., and Peñuelas, J. (2003). Photo- and antioxidative protection, and a role for salicylic acid during drought and recovery in field-grown Phillyrea angustifolia plants. Planta, https://doi.org/10.1007/s00425-00003-01037-00420.

Nxele, X., Klein, A., and Ndimba, B.K. (2017). Drought and salinity stress alters ROS accumulation, water retention, and osmolyte content in sorghum plants. South African Journal of Botany, http://doi.org/10.1016/j.sajb.2016.1011.1003.

Ollas, C.D., Hernando, B., Arbona, V., and Gómez-Cadenas, A. (2013). Jasmonic acid transient accumulation is needed for abscisic acid increase in citrus roots under drought stress conditions. Physiologia Plantarum, http://doi.org/10.1111/j.1399-3054.2012.01659.x.

Park, S., Fung, P., Nishimura, N., Jensen, D., Fujii, H., Zhao, Y., Lumba, S., Santiago, J., Rodrigues, A., Chow, T., et al. (2009). Abscisic acid inhibits type $2 \mathrm{C}$ protein phosphatases via the PYR/PYL family of START proteins. Science, http://doi.org/10.1126/science.1173041. 
Pei, Z., Kuchitsu, K., Ward, J., Schwarz, M., and JI, S. (1997). Differential abscisic acid regulation of guard cell slow anion channels in Arabidopsis wild-type and abil and abi2 mutants. Plant Cell, http://doi.org/10.1105/tpc.1109.1103.1409.

Praba, M.L., Cairns, J.E., Babu, R.C., and Lafitte, H.R. (2009). Identification of Physiological Traits Underlying Cultivar Differences in Drought Tolerance in Rice and Wheat. Journal of Agronomy \& Crop Science, https://doi.org/10.1111/j.1439-1037X.2008.00341.x.

Prudhomme, C., Giuntoli, I., Robinson, E.L., Clark, D.B., Arnell, N.W., Dankers, R., Fekete, B.M., Franssen, W., Gerten, D., and Gosling, S.N. (2014). Hydrological droughts in the 21st century, hotspots and uncertainties from a global multimodel ensemble experiment. Proceedings of the National Academy of Sciences of the United States of America, http://doi.org/10.1073/pnas.1222473110

Reddy, P.S., Divya, K., Sivasakthi, K., Tharanya, M., Lale, A., Bhatnagar, M.P., Kholova, J., Sharma, K.K., and Vadez, V. (2017). Role of pearl millet aquaporin genes in abiotic stress response. In: InterDrought-V. Hyderabad, India, 21-25.

Rollins, J.A., Habte, E., Templer, S.E., Colby, T., Schmidt, J., and Korff, M.v. (2013). Leaf proteome alterations in the context of physiological and morphological responses to drought and heat stress in barley (Hordeum vulgare L.). Journal of Experimental Botany, http://doi.org/10.1093/jxb/ert1158

Samarah, N.H., Alqudah, A.M., Amayreh, J.A., and Mcandrews, G.M. (2009). The Effect of Lateterminal Drought Stress on Yield Components of Four Barley Cultivars. Journal of Agronomy \& Crop Science, http://doi.org/10.1111/j.1439-1037X.2009.00387.x

Sandhu, N., and Kumar, A. (2017). Bridging the Rice Yield Gaps under Drought: QTLs, Genes, and their Use in Breeding Programs Agronomy, https://doi.org/10.3390/agronomy7020027.

Sandhu, N., Singh, A., Dixit, S., Sta Cruz, M., Maturan, P., Jain, R., and Kumar, A. (2014). Identification and mapping of stable QTL with main and epistasis effect on rice grain yield under upland drought stress. Bmc Genetics, http://doi.org/10.1186/1471-2156-1115-1163

Seiler, C., Harshavardhan, V.T., Rajesh, K., Reddy, P.S., Strickert, M., Rolletschek, H., Scholz, U., Wobus, U., and Sreenivasulu, N. (2011). ABA biosynthesis and degradation contributing to ABA homeostasis during barley seed development under control and terminal drought-stress conditions. Journal of Experimental Botany, http://doi.org/10.1093/jxb/erq1446.

Shao, H.B., Chu, L.Y., Lu, Z.H., and Kang, C.M. (2008). Primary antioxidant free radical scavenging and redox signaling pathways in higher plant cells. International journal of biological ences, http://doi.org/10.7150/ijbs.7154.7158.

Shivhare, R., and Lata, C. (2016). Selection of suitable reference genes for assessing gene expression in pearl millet under different abiotic stresses and their combinations. Scientific Reports, http://doi.org/10.1038/srep23036

Shuping, R., Min, S., Haidong, Y., Bingchao, W., and Bing, Z. (2020). Identification and Distribution of NBS-Encoding Resistance Genes of Dactylis glomerata L. and Its Expression Under Abiotic and Biotic Stress. Biochemical Genetics, http://doi.org/10.1007/s10528-10020-09977-10528.

Sifan, Z., Chengran, W., Frazier, T.P., Haidong, Y., Peilin, C., Zhihong, C., Linkai, H., Xinquan, Z., Yan, P., and Xiao, M. (2018). The first Illumina-based de novo transcriptome analysis and molecular marker development in Napier grass ( Pennisetum purpureum ). Molecular Breeding, http://doi.org/10.1007/s11032-11018-10852-11038.

Sun, M., Huang, D., Zhang, A., Khan, I., Yan, H., Wang, X., Zhang, X., Zhang, J., and Huang, L. (2020). Transcriptome analysis of heat stress and drought stress in pearl millet based on Pacbio full-length 
transcriptome sequencing. BMC Plant Biology, http://doi.org/10.1186/s12870-12020-02530-12870.

Szostkiewicz, I., Richter, K., Kepka, M., Demmel, S., Ma, Y., Korte, A., Assaad, F., Christmann, A., and Grill, E. (2010). Closely related receptor complexes differ in their ABA selectivity and sensitivity. Plant J, http://doi.org/10.1111/j.1365-1313X.2009.04025.x.

Tena, G., Asai, T., Chiu, W.L., and Sheen, J. (2001). Plant mitogen-activated protein kinase signaling cascades. Current Opinion in Plant Biology, http://doi.org/10.1016/S1369-5266(1000)00191-00196.

Uzilday, B., Turkan, I., Sekmen, A.H., Ozgur, R., and Karakaya, H.C. (2012). Comparison of ROS formation and antioxidant enzymes in Cleome gynandra (C) and Cleome spinosa (C) under drought stress. Plant ence, http://doi.org/10.1016/j.plantsci.2011.1003.1015.

Vadez, V., Hash, T., Bidinger, F.R., and Kholova, J. (2012). II.1.5 Phenotyping pearl millet for adaptation to drought. Frontiers in Physiology, http://doi.org/10.3389/fphys.2012.00386

Varshney, R.K., Shi, C., Thudi, M., Mariac, C., Wallace, J., Qi, P., Zhang, H., Zhao, Y., Wang, X., Rathore, A., et al. (2017). Pearl millet genome sequence provides a resource to improve agronomic traits in arid environments. Nature Biotechnology, http://doi.org/10.1038/nbt.3943.

Vikram, P., Swamy, M.B., Dixit, S., Ahmed, U.H., Cruz, M.T.S., Singh, A.K., and Kumar, A. (2011). qDTY1.1, a major QTL for rice grain yield under reproductive-stage drought stress with a consistent effect in multiple elite genetic backgrounds. Bmc Genetics, http://doi.org/10.1186/1471-2156-11121189.

Wang, C.J., Yang, W., Wang, C., Gu, C., Niu, D.D., Liu, H.X., Wang, Y.P., and Guo, J.H. (2012). Induction of Drought Tolerance in Cucumber Plants by a Consortium of Three Plant GrowthPromoting Rhizobacterium Strains. Plos One, http://doi.org/10.1371/journal.pone.0052565.

Wang, W., Vinocur, B., and Altman, A. (2003). Plant responses to drought, salinity and extreme temperatures: towards genetic engineering for stress tolerance. Planta, https://doi.org/10.1007/s00425-00003-01105-00425.

Wang, Y., Jiang, J., Zhao, X., Liu, G., Yang, C., and Zhan, L. (2006). A novel LEA gene from Tamarix androssowii confers drought tolerance in transgenic tobacco. Plant ence, http://doi.org/10.1016/j.plantsci.2006.1006.1011.

Wasilewska, A., Vlad, F., Sirichandra, C., Redko, Y., Jammes, F., Valon, C., Frei, d.F.N., and Leung, J. (2008). An update on abscisic acid signaling in plants and more. Mol Plant, http://doi.org/10.1093/mp/ssm1022.

Werner, T., Nehnevajova, E., Kollmer, I., Novak, O., Strnad, M., Kramer, U., and Schmulling, T. (2010). Root-Specific Reduction of Cytokinin Causes Enhanced Root Growth, Drought Tolerance, and Leaf Mineral Enrichment in Arabidopsis and Tobacco. Plant Cell, http://doi.org/10.1105/tpc.1109.072694.

Wilkinson, S., and Davies, W.J. (2010). Drought, ozone, ABA and ethylene: new insights from cell to plant to community. Plant Cell \& Environment, http://doi.org/10.1111/j.1365-3040.2009.02052.x.

Yan, H., Bombarely, A., Xu, B., Wu, B., P, F.T., Zhang, X., Chen, J., Chen, P., Sun, M., and Feng, G. (2019). Autopolyploidization in switchgrass alters phenotype and flowering time via epigenetic and transcription regulation. Journal of Experimental Botany, http://doi.org/10.1093/jxb/erz1325.

Yoshida, R., Umezawa, T., Mizoguchi, T., Takahashi, S., Takahashi, F., and Shinozaki, K. (2006). The Regulatory Domain of SRK2E/OST1/SnRK2.6 Interacts with ABI1 and Integrates Abscisic Acid (ABA) and Osmotic Stress Signals Controlling Stomatal Closure in Arabidopsis. Journal of Biological Chemistry, http://doi.org/10.1074/jbc.M509820200.

Zhang, J., Jia, W., Yang, J., and Ismail, A.M. (2006). Role of ABA in integrating plant responses to 
drought and salt stresses. Field Crops Research, http://doi.org/10.1016/j.fcr.2005.1008.1018.

Zhang, X., Pang, J., Ma, X., Zhang, Z., He, Y., Hirsch, C.N., and Zhao, J. (2019). Multivariate analyses of root phenotype and dynamic transcriptome underscore valuable root traits and water-deficit responsive gene networks in maize. Plant Direct, http://doi.org/10.1002/pld1003.1130.

Zhou, S., Chen, J., Lai, Y., Yin, G., and Liu, L. (2019). Integrative analysis of metabolome and transcriptome reveals anthocyanins biosynthesis regulation in grass species Pennisetum purpureum. Industrial Crops and Products, http://doi.org/10.1016/j.indcrop.2019.111470. 
Figures
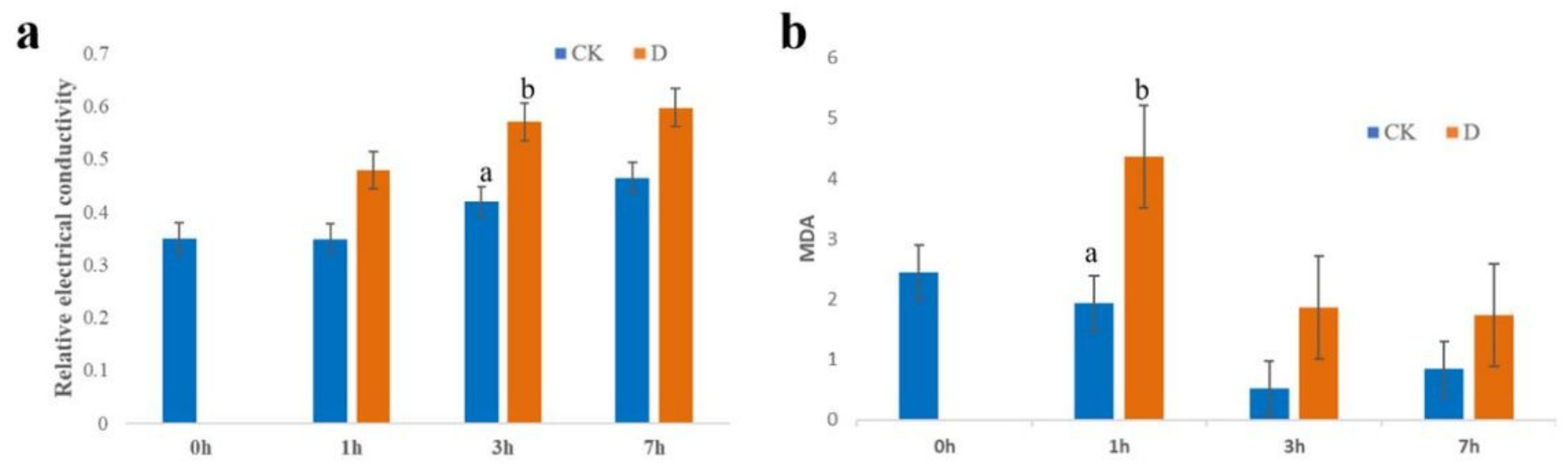

Figure 1

a. the relative conductivity at $0 \mathrm{~h}, 1 \mathrm{~h}, 3 \mathrm{~h}$ and $7 \mathrm{~h}$ of $\mathrm{CK}$ and drought group in root. b. the content of MDA at $\mathrm{Oh}, 1 \mathrm{~h}, 3 \mathrm{~h}$ and $7 \mathrm{~h}$ of $\mathrm{CK}$ and drought group in root.

a

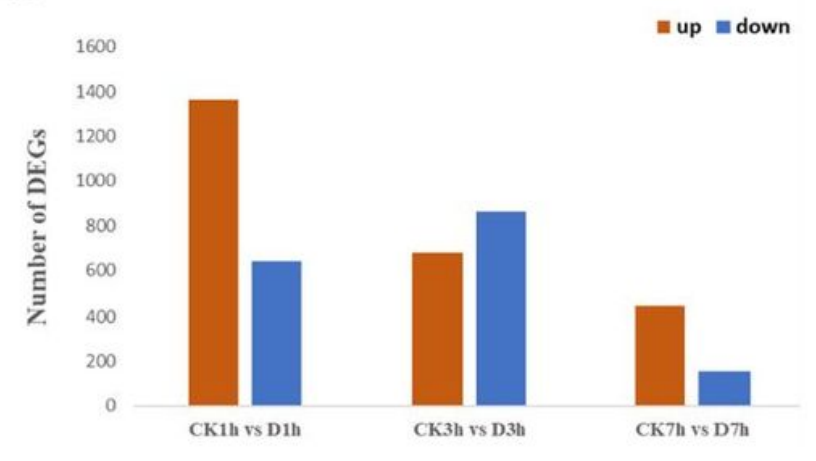

c

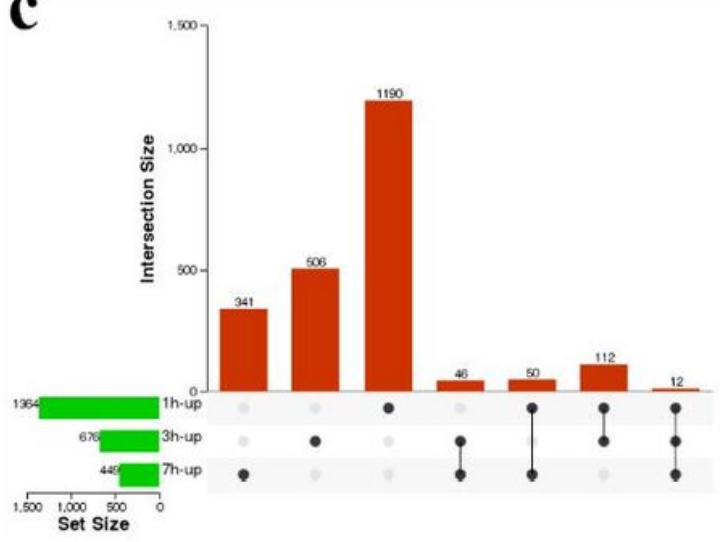

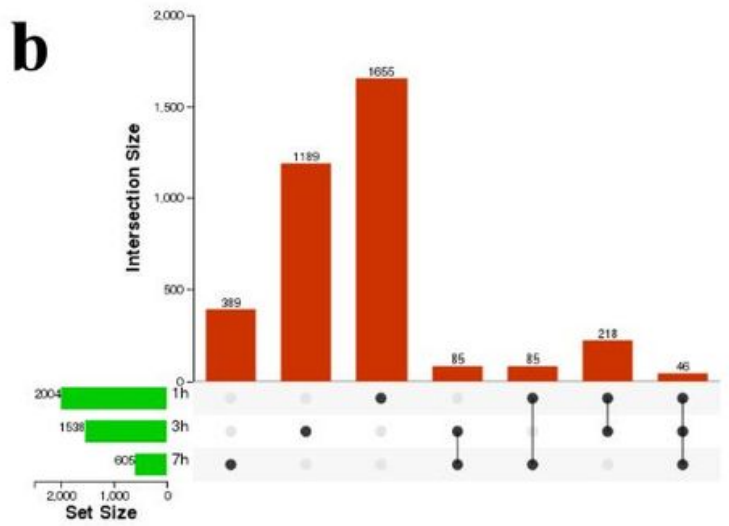

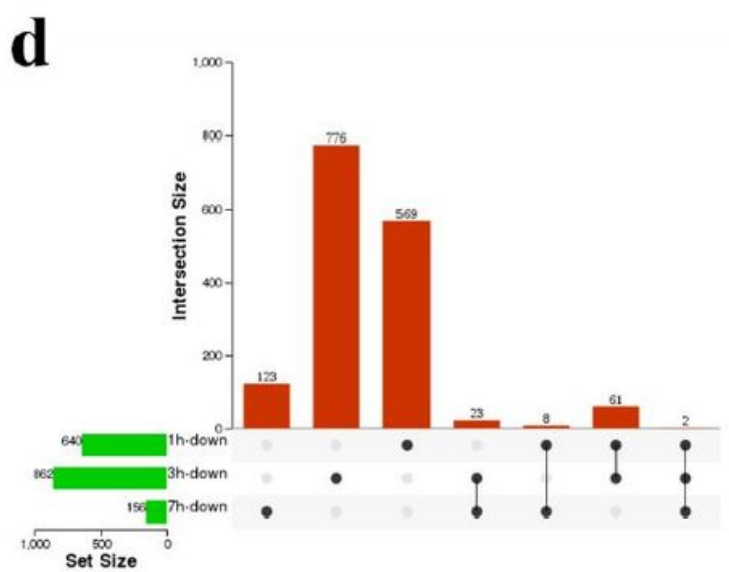

Figure 2 
a. The number of DEGs between CK and drought stress group at $1 \mathrm{~h}, 3 \mathrm{~h}$ and $7 \mathrm{~h} . \mathrm{b}, \mathrm{c}, \mathrm{d}$. DEGs of setup diagram at $1 \mathrm{~h}, 3 \mathrm{~h}$ and $7 \mathrm{~h}$ time points.
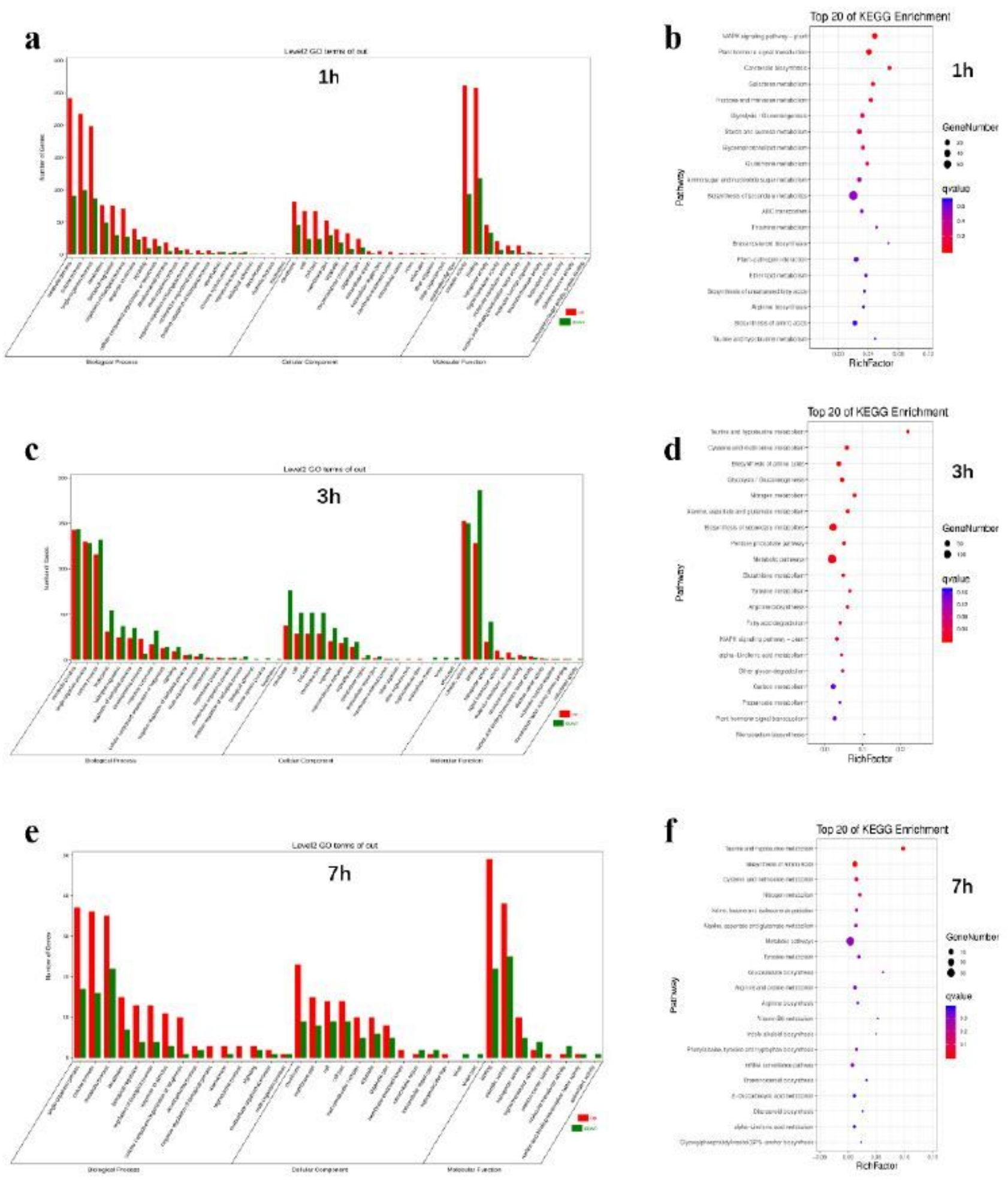

Figure 3

Analysis of DEGs expressing differently between CK and drought stress. a, c, e. GO analysis of DEGs specific to drought stress at $1 \mathrm{~h}, 3 \mathrm{~h}$ and $7 \mathrm{~h} . \mathrm{b}, \mathrm{d}, \mathrm{f}$. KEGG analysis of DEGs specific to drought stress at $1 \mathrm{~h}$, 3h and $7 \mathrm{~h}$. 
$\mathbf{a}$

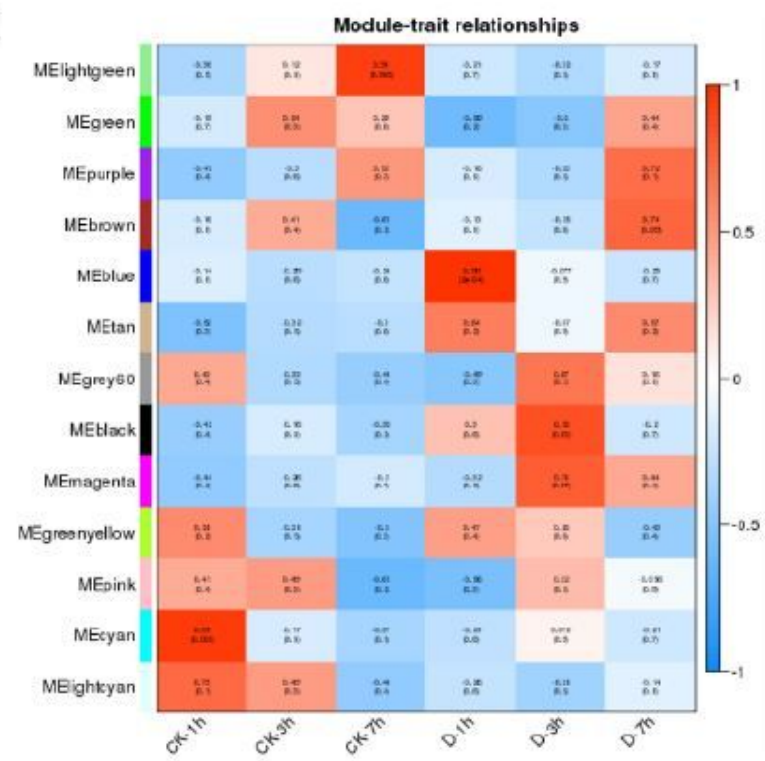

c

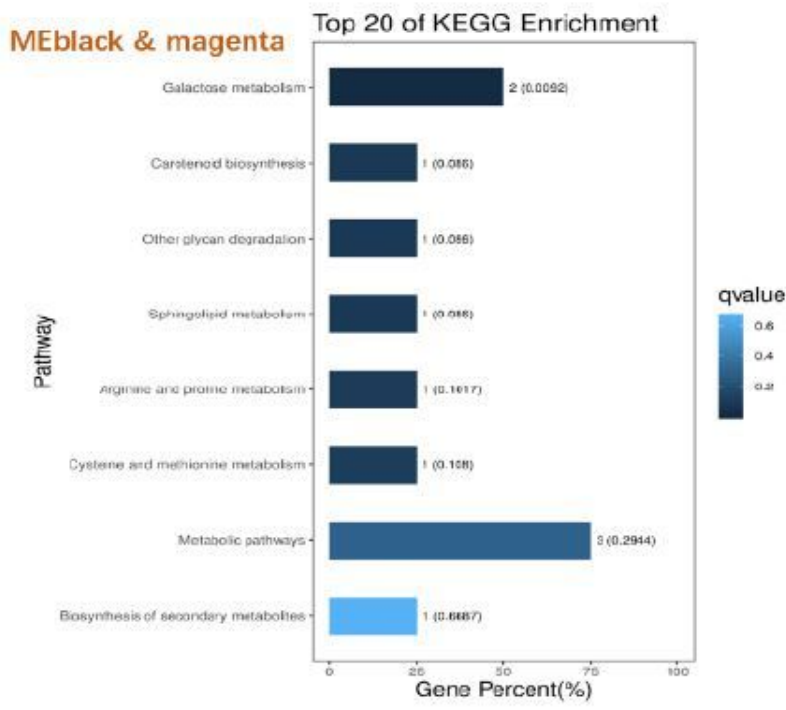

b

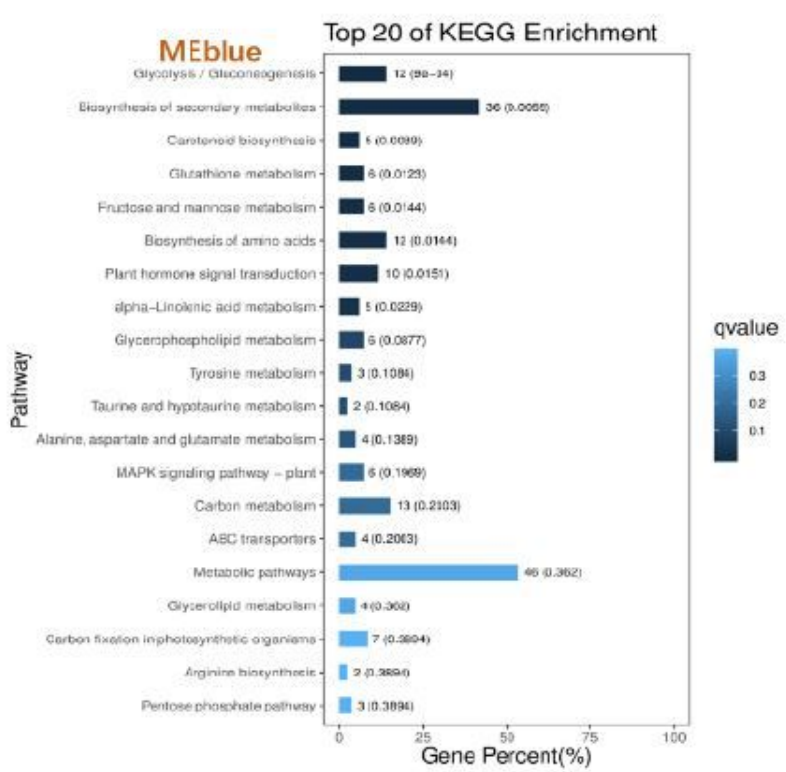

d

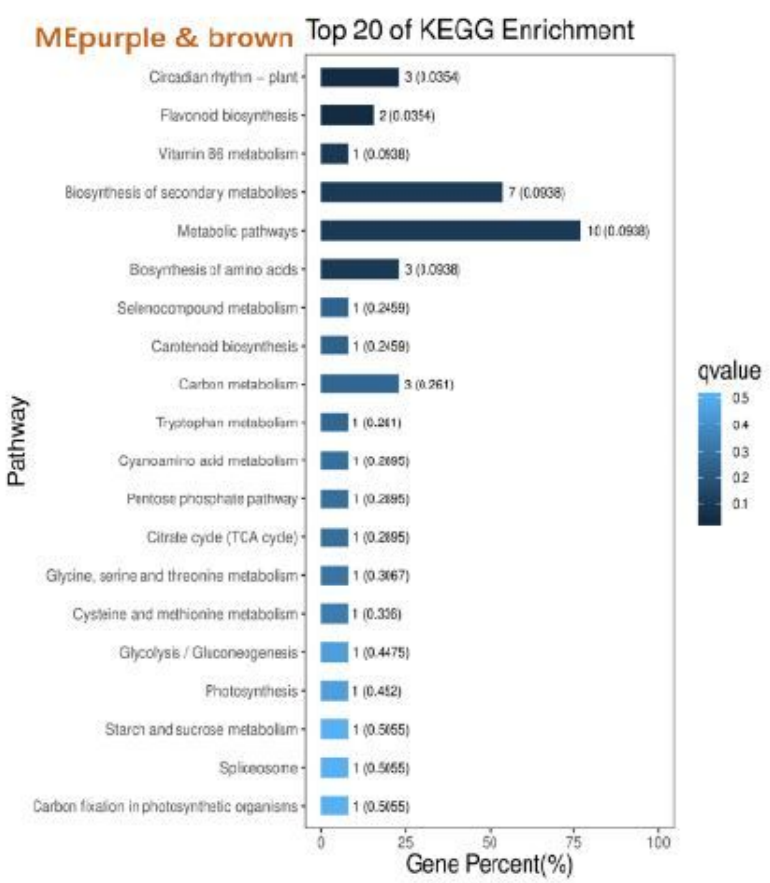

Figure 4

a. A weighted correlation network analysis of genes at 6 groups. b. KEGG analysis of MEblue module. c. KEGG analysis of MEblack and MEmagenta. d. KEGG analysis of MEpurple and MEbrown. 


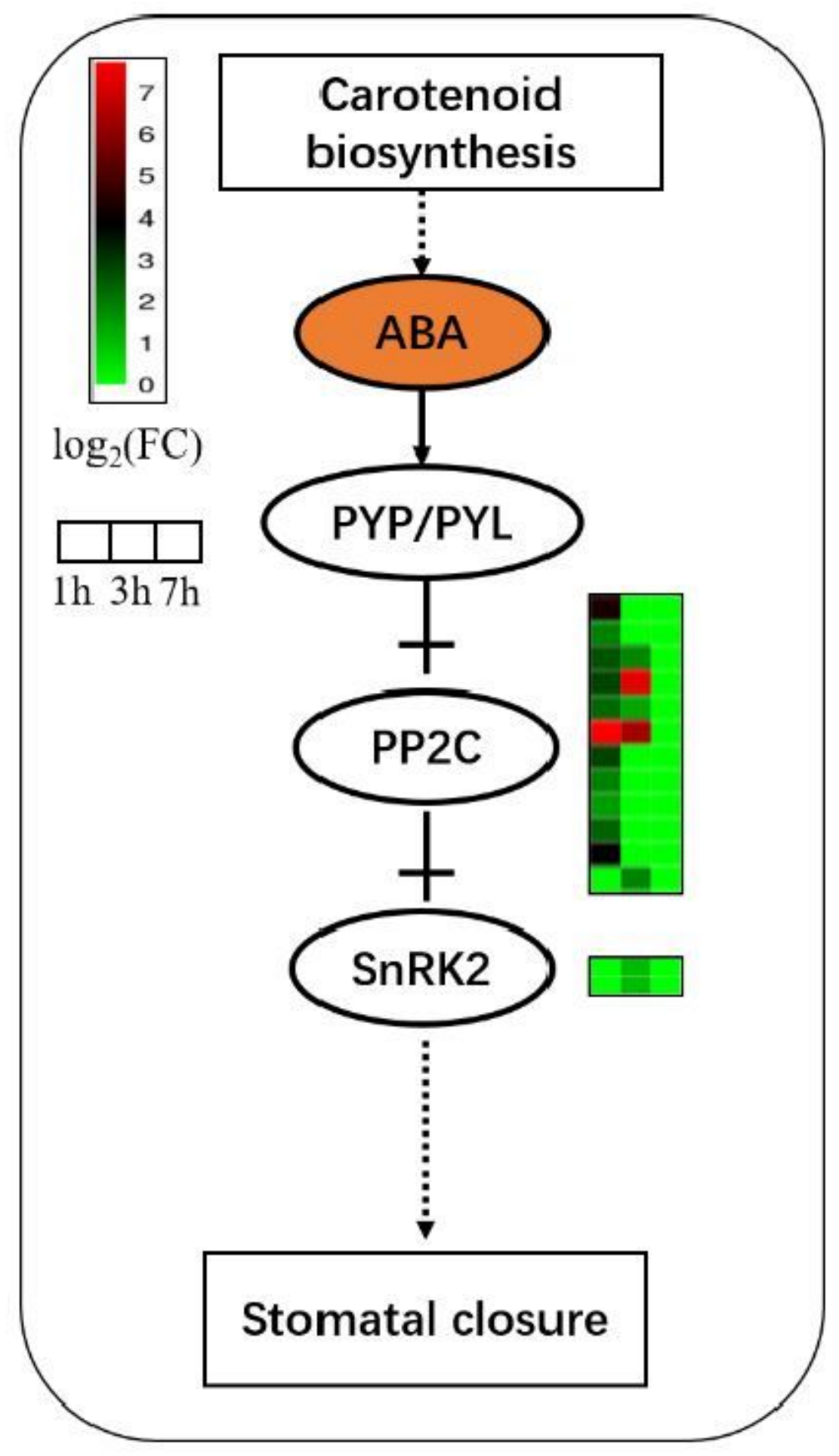

Figure 5

ABA signaling transduction pathway. Heatmaps represent the $\log 2(\mathrm{FC})$ of genes at the corresponding time points.

\section{Supplementary Files}

This is a list of supplementary files associated with this preprint. Click to download. 
- supplementalfigure.docx 